\title{
Precision Measurements of the Dimensional Stability of Four Mirror Materials
}

\author{
B. Justice* \\ Institute for Basic Standards, National Bureau of Standards, Washington, D.C. 20234
}

(April 11, 1975)

\begin{abstract}
There are several glasses and glass-ceramics available today which have low coefficients of thermal expansion-some near zero. For this reason they often serve as substrates for massive mirrors in orbit. In order for such a mirror to enjoy a lifetime of 5 years or more of diffraction-limited service, the substrate must be dimensionally stable and thereby preserve the original figure.

Early in 1967, it was decided that the National Bureau of Standards and Corning Glass Works would undertake a joint effort to measure the lengths of small samples of such materials over a period of years. These measurements were completed in 1971.

The average length changes in parts per million of the four materials ${ }^{1}$ selected are as follows:

Corning Code 9623 a glass ceramic $\quad-0.30$

Corning Code 7971 a titanium silicate $\quad-0.37$

Corning Code 7940 a vitreous silica $\quad-0.47$

Corning Code 9622 a glass-ceramic $\quad-1.03$.
\end{abstract}

Key words: Dimensional stability; glass; glass-ceramic; interferometry.

\section{Technique}

The glass gauge blocks are $1^{\prime \prime} \times 1^{3 / 8^{\prime \prime}} \times 3 / 8^{\prime \prime}$. They were wrung to optical flats at the beginning of the study and never removed. The Zeiss gauge block interferometer at NBS was used with the 5461 A line of $\mathrm{Hg} 198$. The fringe patterns from the top of the sample and from the optical flat on either side relative to a reference flat were recorded on high speed $35 \mathrm{~mm}$ film. It was assumed to be unlikely that the order of interference, 93,000 or so, would change as much as one. Thus we recorded only the fractional displacement of the block fringes relative to the platen fringes.

The negatives were scanned three times by a microdensitometer. The data were smoothed by computer, fringe centers computed, and the fractional displacement at the gauging point calculated.

The interferogram contains 5 to 8 fringes on the gauge block and an equal number on either side from the base flat. All of this occupies a $6 \mathrm{~mm}$ circle on the $35 \mathrm{~mm}$ film. Usually four negatives (two from each of 2 consecutive days) are averaged to obtain a block length. The observed length is corrected for ambient conditions to $20^{\circ} \mathrm{C}, 760 \mathrm{~mm} \mathrm{Hg}$ and $10 \mathrm{~mm}$ of water vapor. The fringes are $\cos ^{2}$ Fizeau fringes.

*The author performed this work while he was an Industrial Research Associate at the National Bureau of Standards: Present address: Corning Glass Works. Research and De velopment Laboratory. Technical Staffs Division. Corning. New York 14830.

${ }^{1}$ The mirror materials are identified by brand name and code number to specify precisely what was measured. This identification does not imply a product endorsement by the $\mathrm{Na}$ tional Bureau of Standards.
The original experiment called for three sets of 12 samples each from each of four materials, for a total of 144 samples. For a number of reasons, we ended up with 94 acceptable survivors and these are reported on here. Some of these samples were exposed to pressure cycling or temperature cycling as described later.

The term "length" in this report refers to the optical length of the gauge block. It includes the physical length, the thickness of the wringing film, and any contribution due to a difference between the phase change upon reflection from the sample and the phase change from the platen. All platens were made of Corning Code 7940 material, a vitreous silica.

\section{Precision}

There are many factors which affect our precision. There are also several improvements we could make in the technique-looking back at the experiment. However, we feel that the limiting precision on good blocks over a long period of time-using this technique as is - is about $6 \sigma=30$ millifringes, or slightly over $0.3 \mathrm{ppm}$.

Precision is affected by the flatness and parallelism of the blocks and platens; by the accuracy of the corrections for atmospheric pressure, temperature, and humidity; by the placement of fringes by the operator and nature over the years; by the fidelity of the photographic record; by the precision we can attain in 
extracting the data from the film; and by the quality of the computer algorithm which converts these data to physical lengths. Some of these areas are discussed below in detail.

The average difference between pairs of negatives made in quick succession for the 1-year data was less than 0.010 fringe. For the latest 3 -year data, this increased to 0.016 fringe, due apparently to poorer image contrast.

A set of 11 negatives, which was exposed September 16 and November 4, 1968, has been used to establish the precision of the technique and the permanence of the photographic information. These same negatives have been measured on five separate occasions. The second and third times were 6 and 29 months after the first, respectively. The fourth and fifth times were on a single day about 31 months after the first, so that the negatives remained in alinement in the microdensitometer for both runs.

The average spread for the first three runs is about 0.005 fringe: for all five runs, it is about 0.0075 fringe, and for the two consecutive runs on $4-26-72$, it is less than 0.003 fringe.

Three scans are made in the $x$ direction at three different $y$ locations. The central sample scan has two symmetric platen scans just $2.3 \mathrm{~mm}$ full scale $(0.46 \mathrm{~mm}$ on the negative) from either edge of the sample. If any $x$ scan is repeated without any adjustments being made, the fringe locations repeat to 0.001 fringe. The fringe separation was 600 to $1200 \mu \mathrm{m}$. Intensity every $8 \mu \mathrm{m}$ was recorded. Recording every two micrometers did not improve the precision enough to justify the expense of handling four times as much data.

Since the image of the block is only $2000 \mu \mathrm{m}$ in width, an error of $25 \mu \mathrm{m}$ in alinement will produce an error of 0.003 fringe with an out of parallel of 0.25 fringe, across the $9500 \mu \mathrm{m}\left(3 / 8^{\prime \prime}\right)$ face.

The data are as follows:

\begin{tabular}{|c|c|c|c|c|c|}
\hline \multicolumn{6}{|c|}{ Displacement in Fringe Fractions for Card 104} \\
\hline \multirow{2}{*}{ Film No. } & \multicolumn{5}{|c|}{ Date Measured } \\
\hline & $9-30-69$ & $3-20-70$ & $2-16-72$ & $4-26-72 \mathrm{~A}$ & $4-26-72 B$ \\
\hline $1 \ldots$ & 0.8444 & 0.8411 & 0.8423 & 0.8469 & 0.8441 \\
\hline $2 \ldots$ & .8422 & .8417 & .8432 & .8471 & .8435 \\
\hline 3. & .7077 & .7070 & .7035 & .7093 & .7113 \\
\hline $4 .$. & .7098 & .7151 & .7148 & .7160 & .7177 \\
\hline 5. & .0913 & .0856 & .0866 & .0900 & .0922 \\
\hline 6. & .0919 & .0893 & .0896 & .0905 & .0937 \\
\hline 7. & .7314 & .7362 & .7300 & .7330 & .7309 \\
\hline 8. & .7444 & .7427 & .7379 & .7458 & .7430 \\
\hline 9. & .2961 & .2866 & .2959 & .2987 & .3014 \\
\hline $10 \ldots$ & .2894 & .2836 & .2869 & .2900 & .2939 \\
\hline $11 \ldots$ & .3053 & .3015 & .3044 & .3070 & .3044 \\
\hline Avg. & .5140 & .5119 & .5123 & .5158 & .5160 \\
\hline $\begin{array}{l}\text { Deviation } \\
\text { from Grand } \\
\text { mean......... }\end{array}$ & 0.0000 & -0.0021 & -0.0017 & +0.0018 & +0.0020 \\
\hline
\end{tabular}

It is apparent that 1 and 2,3 , and 4 etc. are repeat negatives of the same block.
Two of the three microdensitometer scans are on the base flat along either side of the gauge block. The third is halfway between, down the center of the block. The computer reports all fringe and crosshair positions detected. It also reports halfwidths and intensities. The program, however, uses only two of the block fringes and the next surrounding pairs of platen fringes.

The program might well have been written to be more informative by putting to use all of the incidental data. As an example, table 1 shows the intervals in micrometers between successive pairs of the six fringes detected on film 1 of card 104 for the five runs described before.

Table 1. Precision of Fringe Placement for Film 1 on Card 104

\begin{tabular}{|c|c|c|c|c|c|c|}
\hline \multicolumn{7}{|c|}{ Left Platen Scan } \\
\hline $9-30-69$ & 913 & 913 & 903 & 959 & 950 & 927.6 \\
\hline $3-20-70$ & 908 & 915 & 897 & 966 & 947 & 926.6 \\
\hline $2-16-72$ & 912 & 912 & 908 & 959 & 942 & 926.6 \\
\hline $4-26-72$ & 907 & 915 & 909 & 954 & 948 & 926.6 \\
\hline $4-26-72$ & 905 & 915 & 909 & 954 & 949 & 926.4 \\
\hline & 909 & 914 & 905 & 958 & 947 & 926.8 \\
\hline \multicolumn{7}{|c|}{ Sample Scan } \\
\hline $9-30-69$ & 973 & 975 & 955 & 989 & 969 & 972.2 \\
\hline $3-20-70$ & 964 & 974 & 955 & 985 & 974 & 970.4 \\
\hline $2-16-72$ & 971 & 971 & 957 & 987 & 968 & 970.8 \\
\hline $4-26-72$ & 965 & 974 & 958 & 984 & 973 & 970.8 \\
\hline \multirow[t]{2}{*}{$4-26-72$} & 964 & 975 & 958 & 984 & 973 & 970.8 \\
\hline & 967 & 974 & 957 & 986 & 971 & 971.0 \\
\hline \multicolumn{7}{|c|}{ Right Platen Scan } \\
\hline $9-30-69$ & 933 & 876 & 938 & 946 & 955 & 929.6 \\
\hline $3-20-70$ & 931 & 874 & 939 & 943 & 957 & 928.8 \\
\hline $2-16-72$ & 941 & 875 & 938 & 943 & 947 & 928.8 \\
\hline $4-26-72$ & 931 & 875 & 942 & 940 & 955 & 928.6 \\
\hline \multirow[t]{2}{*}{$4-26-72$} & 930 & 875 & 943 & 938 & 956 & 928.4 \\
\hline & 933 & 874 & 940 & 942 & 954 & 928.8 \\
\hline
\end{tabular}

Several conclusions can be drawn about the sample and the flat, as they were in the fall of 1968. The conclusions are based upon those points of the surfaces intersected by the three densitometer scans.

For example:

(1) The left platen surface lacks about 0.002 fringe of being parallel to the right platen surface, in the areas scanned.

(2) The sample surface is about 0.047 fringe out of parallel with the platen surface.

(3) The three surfaces have localized areas out of flat by as much as 0.057 fringe, 0.030 fringe and 0.085 fringe respectively.

(4) The Kodak 2485 film $^{2}$ with an Estar base must

${ }^{2}$ Certain commercial products are identified in order to adequately specify the experi mental procedure. In no case does such identification imply recommendation or endorsement by the National Bureau of Standards nor does it imply that the products identified are necessarily the best available for the purpose. 
itself be dimensionally stable over the 31 months, to within a few parts per thousand.

(5) The sample surface is more nearly flat than the platen surfaces. The average deviation from a leastsquares straight lir.e is only four parts in 970, for the sample surface.

(6) The average discrepancy in fringe location for two successive runs is about $2 / 3$ micrometer.

\section{Environments}

A set usually consists of nine 1 -inch gauge blocks $\left(3 / 8^{\prime \prime} \times 13 / 8^{\prime \prime}\right)$ wrung to a Corning Code 7940 optical flat. The Corning Code 9622 experienced ambient conditions only. The three other materials also had additional sets which were subjected to uniaxial compression cycling, parallel to the gauging direction, from 0 to about $14.1 \mathrm{Kg} / \mathrm{cm}^{2}$, or to temperature cycling from $-2^{\circ}$ to $+52^{\circ}$ Celsius. The time required for either cycle was $1 \mathrm{~h}$. A series of $1,10,100$, and 1,000 total cycles was used. These forced environments were all completed between the 60-day and 365-day data. Except for this total 1,000 hours, all other storage was in the same well-controlled room with the "ambient" samples. Ambient humidity during the measurements had values ranging from 22 to $62 \%$ R.H.

\section{Summary of Data}

All but some of the earliest data consist of the average of four interferograms, two from each of two usually consecutive days. Zero time was the day of the first measurement. The other reported dates are near the 1 month, 6 months, 1-, 2-, and 3-year intervals. See tables 2 through 5 . These data were normalized by reporting the deviation of each block about its mean for 3 years $(3.1-3.4)$ in millifringes. A value of 50 , for example, is equivalent to 0.050 fringe, or about 0.54 microinch.

Listed below is a summary from tables 2 through 5 , which ranks these four materials in order of decreasing stability. The shrinkage figures in parentheses are the values obtained if one averages the first two data

TABLE 2. Individual Length Changes in Millifringes

\begin{tabular}{|c|c|c|c|c|c|c|c|}
\hline \multicolumn{8}{|c|}{ Corning Code 9623, Pressure } \\
\hline Days & 0 & 53 & 156 & 373 & 772 & 1238 & $\Delta$ \\
\hline Sample: & & & & & & & \\
\hline A $-2-7 *$ & -1 & 0 & -14 & 5 & 13 & -4 & -3 \\
\hline 8* & -9 & 2 & -33 & 10 & 22 & 8 & 17 \\
\hline 9*. & -7 & -9 & -4 & 10 & 17 & -5 & 2 \\
\hline $11 *$. & 3 & -1 & -10 & -6 & 14 & 3 & 0 \\
\hline $12 *$ & 8 & 9 & -22 & 0 & 9 & -1 & -9 \\
\hline $13 *$. & 9 & -1 & -4 & 6 & 3 & -10 & -19 \\
\hline $15 *$. & -13 & -5 & -4 & 17 & 8 & 0 & 13 \\
\hline $16^{*}$. & 25 & 20 & -31 & 1 & -8 & -9 & -34 \\
\hline $17 \ldots$ & 30 & 30 & -19 & 0 & -4 & -34 & -64 \\
\hline Average.. & 5 & 5 & -16 & 5 & 8 & -6 & -11 \\
\hline
\end{tabular}

TABLE 2. Individual Length Changes in Millifringes-Continued

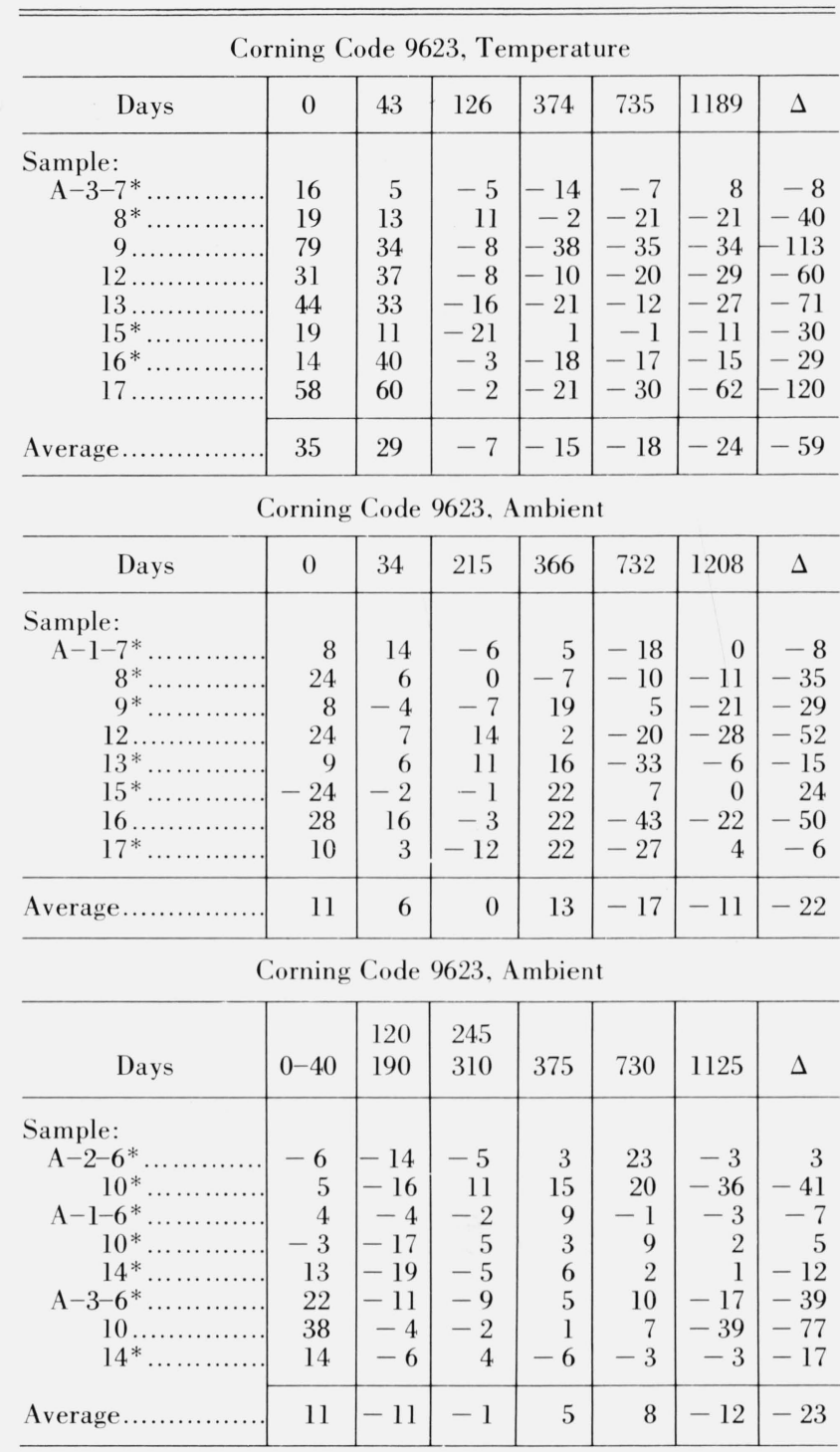

points, which were less than 60 days apart. Shrinkage ranges from about $1 / 4$ to $1 \mathrm{~nm}$ per $\mathrm{mm}(1 / 4$ to 1 microinch per inch) over $3+$ year period.

TABLE 3. Individual length changes in millifringes

\begin{tabular}{|c|c|c|c|c|c|c|c|}
\hline \multicolumn{8}{|c|}{ Corning Code 7971, Pressure } \\
\hline Days & $0-6$ & 45 & 118 & 372 & 730 & 1192 & $\Delta$ \\
\hline $\begin{array}{r}\text { Sample: } \\
\text { D-2-7*.. } \\
11 \ldots \\
13^{*} . . \\
15^{*} . . \\
16 \ldots\end{array}$ & $\begin{array}{r}35 \\
33 \\
17 \\
-6 \\
31\end{array}$ & $\begin{array}{l}18 \\
12 \\
20 \\
11 \\
50\end{array}$ & $\begin{array}{r}6 \\
9 \\
4 \\
-6 \\
14\end{array}$ & $\begin{array}{r}-27 \\
-14 \\
-7 \\
18 \\
-21\end{array}$ & $\begin{array}{r}-31 \\
-22 \\
-23 \\
-5 \\
-43\end{array}$ & $\begin{array}{r}-3 \\
-15 \\
-11 \\
-9 \\
-30\end{array}$ & $\begin{array}{r}-38 \\
-48 \\
-28 \\
-3 \\
-61\end{array}$ \\
\hline Average.... & 22 & 22 & 5 & -10 & -25 & -14 & -36 \\
\hline
\end{tabular}


TABLE 3. Individual length changes in millifringes-Continued

Corning Code 7971, Temperature

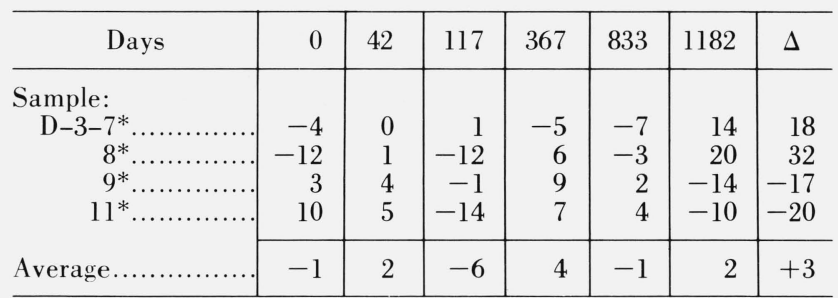

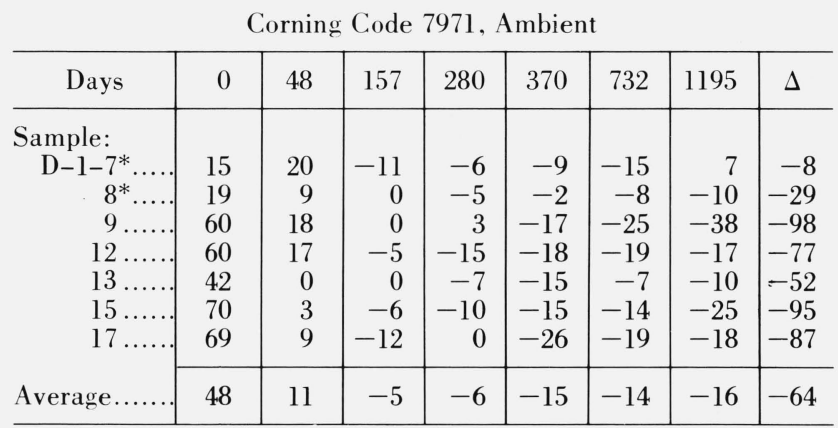

Corning Code 7971, Ambient

\begin{tabular}{|c|c|c|c|c|c|c|c|}
\hline Days & $0-40$ & $\begin{array}{l}120 \\
190\end{array}$ & $\begin{array}{l}245 \\
310\end{array}$ & 375 & 730 & 1125 & $\Delta$ \\
\hline $\begin{array}{l}\text { Sample: } \\
\text { D-2-6* }\end{array}$ & 10 & -2 & 3 & -4 & 2 & -9 & -19 \\
\hline $\begin{array}{r}5-2-0 \\
10\end{array}$ & $\begin{array}{l}10 \\
32\end{array}$ & -5 & $\begin{array}{r}5 \\
-9\end{array}$ & 2 & $\begin{array}{l}2 \\
3\end{array}$ & -22 & $\begin{array}{l}-19 \\
-54\end{array}$ \\
\hline 14 & 4 & 4 & 23 & 54 & -35 & -50 & -54 \\
\hline D-1-6*. & 14 & -9 & -3 & 10 & 0 & -13 & -27 \\
\hline $10 \ldots$ & 30 & -2 & 7 & 2 & -7 & -28 & -58 \\
\hline D-3-6*. & 8 & -8 & 6 & -13 & 5 & 5 & -3 \\
\hline $10^{*}$ & -13 & 8 & 8 & 24 & -5 & -22 & -9 \\
\hline $14^{*}$ & -25 & -37 & 25 & 17 & 23 & -5 & 20 \\
\hline Average... & 8 & -6 & 8 & 12 & -1 & -18 & -26 \\
\hline
\end{tabular}

TABLE 4. Individual length changes in millifringes

\begin{tabular}{|c|c|c|c|c|c|c|c|}
\hline \multicolumn{8}{|c|}{ Corning Code 7940 , Pressure } \\
\hline Days & 0 & 31 & 129 & 371 & 730 & 1182 & $\Delta$ \\
\hline $\begin{array}{r}\text { Sample: } \\
\text { C-3-7 } \ldots \\
8 \ldots \\
9 \ldots \\
11 \ldots \\
12 \ldots \\
13^{*} . \\
15 \ldots \\
16^{*} .\end{array}$ & $\begin{array}{r}44 \\
69 \\
66 \\
36 \\
91 \\
35 \\
31 \\
6\end{array}$ & $\begin{array}{r}29 \\
59 \\
42 \\
29 \\
62 \\
31 \\
32 \\
0\end{array}$ & $\begin{array}{r}-17 \\
-40 \\
-37 \\
-41 \\
-10 \\
-29 \\
-1 \\
11\end{array}$ & $\begin{array}{r}-19 \\
-34 \\
-29 \\
-2 \\
-44 \\
-10 \\
-7 \\
-11\end{array}$ & $\begin{array}{l}-18 \\
-31 \\
-35 \\
-10 \\
-63 \\
-34 \\
-33 \\
-20\end{array}$ & $\begin{array}{r}-19 \\
-23 \\
-9 \\
-9 \\
-38 \\
5 \\
-20 \\
14\end{array}$ & $\begin{array}{r}-63 \\
-92 \\
-75 \\
-45 \\
-129 \\
-30 \\
-51 \\
8\end{array}$ \\
\hline Average.... & 47 & 36 & -21 & -20 & -31 & -12 & -59 \\
\hline
\end{tabular}

TABLE 4. Individual length changes in millifringes-Continued

\begin{tabular}{|c|c|c|c|c|c|c|c|}
\hline \multicolumn{8}{|c|}{ Corning Code 7940 , Temperature } \\
\hline Days & 0 & 34 & 132 & 372 & 739 & 1213 & $\Delta$ \\
\hline 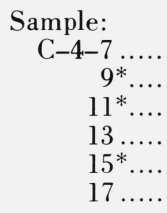 & $\begin{array}{r}28 \\
23 \\
-17 \\
21 \\
16 \\
45\end{array}$ & $\begin{array}{l}36 \\
23 \\
30 \\
33 \\
32 \\
47\end{array}$ & $\begin{array}{r}19 \\
7 \\
5 \\
-13 \\
-8 \\
20\end{array}$ & $\begin{array}{r}-23 \\
-16 \\
0 \\
-7 \\
-9 \\
-3\end{array}$ & $\begin{array}{r}-33 \\
-16 \\
-10 \\
-7 \\
-7 \\
-51\end{array}$ & $\begin{array}{r}-26 \\
-20 \\
-5 \\
-26 \\
-23 \\
-59\end{array}$ & $\begin{array}{r}-54 \\
-43 \\
12 \\
-47 \\
-39 \\
-104\end{array}$ \\
\hline Average.. & 19 & 33 & 5 & -10 & -21 & -26 & -45 \\
\hline \multicolumn{8}{|c|}{ Corning Code 7940, Ambient } \\
\hline Days & $0-18$ & $49^{\prime}$ & 162 & 370 & 734 & 1215 & $\Delta$ \\
\hline $\begin{array}{r}\text { Sample: } \\
\text { C-2-7*... } \\
8^{*} \ldots \\
11 \ldots \\
12 \ldots \\
13^{*} \ldots \\
15^{*} \ldots \\
16^{*} \ldots \\
17 \ldots\end{array}$ & $\begin{array}{r}1 \\
36 \\
31 \\
23 \\
8 \\
15 \\
6 \\
6 \\
27\end{array}$ & $\begin{array}{r}3 \\
9 \\
29 \\
41 \\
2 \\
34 \\
2 \\
37\end{array}$ & $\begin{array}{r}-2 \\
-3 \\
-1 \\
5 \\
-12 \\
-8 \\
2 \\
-15\end{array}$ & $\begin{array}{r}15 \\
-12 \\
-19 \\
1 \\
33 \\
7 \\
14 \\
4\end{array}$ & $\begin{array}{l}-17 \\
-41 \\
-28 \\
-41 \\
-22 \\
-23 \\
-21 \\
-33\end{array}$ & $\begin{array}{r}0 \\
11 \\
-13 \\
-27 \\
-11 \\
-23 \\
-3 \\
-19\end{array}$ & $\begin{array}{r}-1 \\
-25 \\
-44 \\
-50 \\
-19 \\
-38 \\
-9 \\
-46\end{array}$ \\
\hline Average.... & 18 & 20 & -4 & 5 & -28 & -11 & -29 \\
\hline \multicolumn{8}{|c|}{ Corning Code 7940, Ambient } \\
\hline Days & $0-40$ & $\begin{array}{l}120 \\
190\end{array}$ & $\begin{array}{l}245 \\
310\end{array}$ & 375 & 730 & 1125 & $\Delta$ \\
\hline 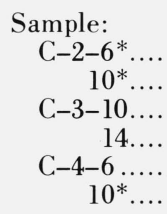 & $\begin{array}{r}6 \\
23 \\
22 \\
39 \\
24 \\
-10\end{array}$ & $\begin{array}{r}7 \\
-11 \\
9 \\
0 \\
-5 \\
-13\end{array}$ & $\begin{array}{r}-8 \\
2 \\
3 \\
-14 \\
8 \\
17\end{array}$ & $\begin{array}{r}3 \\
8 \\
-10 \\
-10 \\
7 \\
12\end{array}$ & $\begin{array}{r}1 \\
-4 \\
20 \\
7 \\
-2 \\
5\end{array}$ & $\begin{array}{r}-6 \\
-18 \\
-45 \\
-24 \\
-29 \\
-9\end{array}$ & $\begin{array}{r}-12 \\
-41 \\
-67 \\
-63 \\
-53 \\
1\end{array}$ \\
\hline Average..... & 17 & -2 & 1 & 2 & 4 & -22 & -39 \\
\hline
\end{tabular}

TABLE 5. Individual Length Changes in Millifringes

\begin{tabular}{r|r|r|r|r|r|r|r|r}
\hline \hline \multicolumn{7}{c}{ Corning Code 9622, Ambient } \\
\hline Days & $0-18$ & $42-124$ & 270 & 381 & 487 & 685 & 1125 & $\Delta$ \\
\hline Sample: & & & & & & & & \\
E-1-7..... & 50 & 30 & 12 & 6 & -20 & -20 & -55 & -105 \\
$8 \ldots \ldots$ & 51 & 25 & 13 & 4 & -15 & -28 & -47 & -98 \\
$9 \ldots \ldots$ & 51 & 31 & 12 & -5 & -18 & -26 & -45 & -96 \\
$11 \ldots \ldots$ & 54 & 39 & 14 & 4 & -26 & -36 & -51 & -105 \\
$12 \ldots \ldots$ & 48 & 27 & 23 & 2 & -23 & -30 & -44 & -92 \\
$13 \ldots \ldots$ & 56 & 17 & -8 & 16 & -18 & -19 & -42 & -98 \\
$15 \ldots \ldots$ & 60 & 12 & 5 & 10 & -24 & -42 & -23 & -83 \\
$16 \ldots \ldots$ & 52 & 19 & 9 & 10 & -23 & -21 & -46 & -98 \\
$17 \ldots \ldots$ & 51 & 8 & 5 & -4 & -11 & -18 & -34 & -85 \\
\cline { 2 - 9 } Average $\ldots \ldots$. & 53 & 23 & 9 & 5 & -20 & -27 & -43 & -96 \\
\hline
\end{tabular}




\begin{tabular}{|c|c|c|c|c|c|}
\hline & $\begin{array}{l}\text { Number } \\
\text { of } \\
\text { Samples }\end{array}$ & $\begin{array}{l}\text { Average Total Change } \\
\text { in Millifringes }\end{array}$ & $\begin{array}{l}\text { Range of } \\
\text { Individuals }\end{array}$ & $\begin{array}{c}\% \\
<40 \mathrm{mf}\end{array}$ & $\begin{aligned} & \% \\
> & 80 \mathrm{mf}\end{aligned}$ \\
\hline Corning Code $9623 \ldots \ldots \ldots$ & 33 & $-28(-24)$ & +24 to -120 & 76 & 6 \\
\hline Corning Code $7971 \ldots . . . .$. & 24 & $-34 \quad(-29)$ & +32 to -98 & 58 & 12 \\
\hline Corning Code $7940 \ldots \ldots \ldots$ & 28 & $-44(-41)$ & +12 to -129 & 46 & 11 \\
\hline Corning Code $9622 \ldots \ldots \ldots$ & 9 & $-96(-81)$ & -81 to -150 & 0 & 100 \\
\hline
\end{tabular}

The Code 9622 shows the greatest average shrinkage but indicates extremely uniform and more nearly predictable performance. Figure 1 shows the average deviation of the nine blocks about their means as a function of time. The average individual variation about the average is only $\pm 12 \mathrm{mf}$. The curve is based upon shrinkage in any year being 58 percent of the previous year's shrinkage.

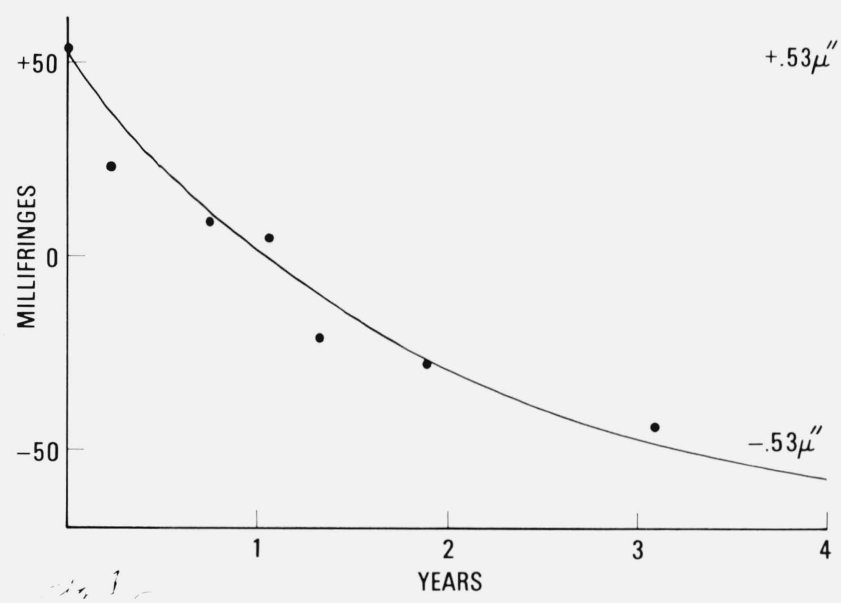

FigURE 1. Code 9622 - average length versus time.

In tables 2 through 5 , the $\Delta$ column is simply the 3 -year value minus the time zero value. The asterisks denote those samples whose $\Delta$ is about $40 \mathrm{mf}$ or less. Of the 94 samples, 52 are in this category of being quite stable. However, 32 of these have a $\Delta$ of $20 \mathrm{mf}$ or less. These samples, therefore, exhibit dimensional stability to something less than $0.07 \mathrm{ppm} /$ year. Sixteen of these 32 blocks are Corning Code 9623 glass-ceramic.

\section{Conclusions}

The conclusions to be drawn are:

(1) About half of these samples exhibit length stability at least as good as $0.4 \mathrm{ppm}$ for 3 years. About 40 percent are better than $0.3 \mathrm{ppm}$, about the precision of the experiment.

(2) Other samples, notably Code 9622 material, may shrink as much as $1 \mathrm{ppm}$ in 3 years.

\section{Statistical Analysis}

A two-part, statistical analysis of the data was made by standard techniques. The first part was a test of the contributions made by barometric pressure, temperature and humidity to the observed variation in length. If one measures these three atomospheric parameters exactly and corrects precisely for optical path and thermal expansion, then there would be no significant contribution to the observed length.

In many instances, however, this was not the case. The following table lists the confidence level at which we can say that barometric pressure, or temperature, or humidity explains a significant portion of the variance in length. (Cases less than $90 \%$ confident are not included).

\begin{tabular}{|c|c|c|c|}
\hline & Baro. Press. & Temp. & Humidity \\
\hline 9623 (pressure environment).. & $90 \%$ & $95 \%$ & $99 \%$ \\
\hline 7940 (pressure environment).. & $90 \%$ & & \\
\hline 9623 (temp. cycling).............. & \multirow{5}{*}{$99 \%$} & $95 \%$ & \\
\hline 7940 (temp. cycling).... & & $90 \%$ & \\
\hline 7940 (ambient)............. & & & $90 \%$ \\
\hline 7971 (ambient)..... & & & \\
\hline 9622 (ambient)..... & & & a $89 \%$ \\
\hline
\end{tabular}

a Code 9622 showed a large time-dependent shrinkage. These values fit several mathematical equations quite well. The residuals from the best-fitting curve-i.e., subtracting out the time-dependent length change - were then tested in the same manner for contributions by barometric pressure, temperature, and humidity. At the 89 percent level of confidence, humidity was making a significant contribution to this residual length variance. The equation of the form $\Delta L=a e^{-b t}$ accounted for 88.1 percent of the length variation with time.

There appears to be neither a consistent measurement error, nor a fixed correction error. There is, however, adequate suspicion to encourage one to make such measurements in vacuum. In this way, all of the pressure, humidity, and temperature contributions to the refractive index would be eliminated - only a very slight (for these materials) thermal expansion effect would remain.

The second part of the statistical analysis was an analysis of variance with change in length as the dependent variable, and material, environment, side finish, and orientation, as the independent variables.

\subsection{Material}

At the 99.4 percent level of significance there is a difference among the four materials. When the Code 9622 glass-ceramic is excluded, this drops to 77.5 percent - that is probably no significant difference.

\subsection{Code 7971 Titanium Silicate}

At the 92.4 percent level of significance, using data 
from all environments and all side finishes, there is a difference due to the orientation of the gauging dimension in the original boule of glass. Those with the gauging dimension parallel to the axis of the boule showed the greatest shrinkage.

This significance may be appearing higher than it really is, due to moderate interaction between side finish and environment which showed up on a two-way analysis of variance. When orientation was tested, using only data from an ambient environment and acid relieved side finish, the significance dropped to 79.1 percent.

\subsection{Code 9623 Glass-Ceramic}

At the 99.7 percent level of significance, there is a difference due to side finish, that is, some of the blocks had the nongauging surfaces polished, or acid relieved, or left as ground. The polished samples showed greatest shrinkage.

At the 98.9 percent level of significance, there is a difference due to environment. The temperature cycling environment showed the greatest shrinkage.

\subsection{Code 7940 Vitreous Silica}

Orientation, side finish, and environment had no significant effect upon the dimensional stability of Code 7940 glass.

\subsection{Code 9622 Glass-Ceramic}

Only orientation could be tested and it proved to be probably not significant -79.2 percent level.

The original experiment was not designed to fully characterize the effects of the numerous variations of finish, environment, and orientation. The majority of samples were acid-relieved and stored at ambient temperature. This left very few samples, due to economic considerations, in the other possible combinations. For this reason, and because of the apparent interaction between some of the variables, the summary just given might better be used with some degree of caution.

I am indebted to many people at the National Bureau of Standards, but the work would not have gotten done without the unfailing assistance of Clyde Tucker, who patiently shot and reshot many thousands of interferograms.

(Paper 79A4-857) 